\title{
Conveying Science through Art Professional Development Experience: Participant Takeaways and Recommendations for the Future
}

\author{
An Evaluation Report Prepared for Guerilla Science and Pratt \\ Institute
}

Prepared by:

Kari O'Connell

Martin Storksdieck

STEM Research Center

Oregon State University

254 Gilbert Hall

Corvallis, OR 97331

April 19, 2020

Cite as:

O'Connell, K., \& Storksdieck, M. (2020): Conveying Science through Art Professional Development Experience: Participant Takeaways and Recommendations for the Future. Technical Report. Corvallis, OR: Oregon State University. 


\section{Table of Contents}

Conveying Science through Art Professional Development Experience: Participant Takeaways and Recommendations for the Future .................................................. 1

An Evaluation Report Prepared for Guerilla Science and Pratt Institute ....................... 1

Table of Contents............................................................................................ 2

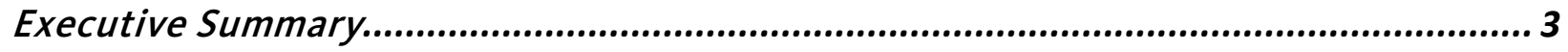

Key Findings ...................................................................................................... 4

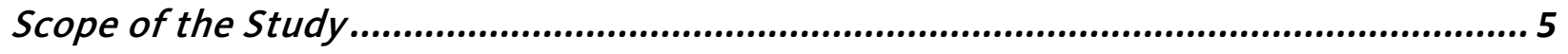

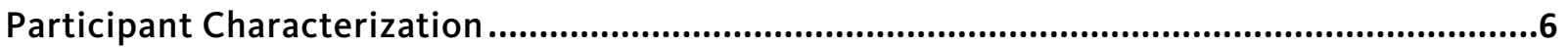

Quality and Usefulness of the Workshop and Field Experience ............................................7

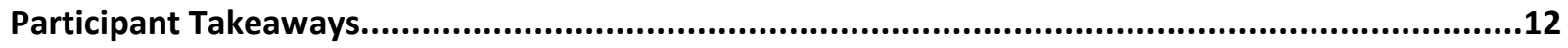

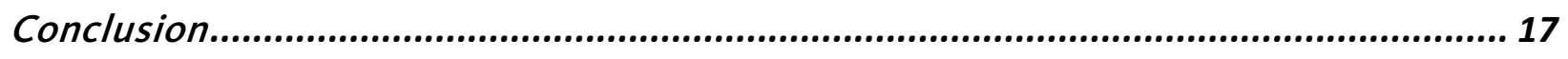

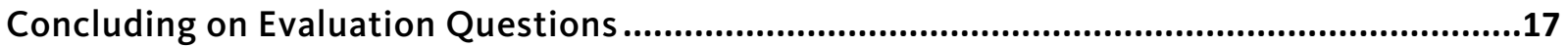

Recommendations for Future Professional Development ....................................................17

Technical Appendix (Methods) ......................................................................... 18 


\section{Executive Summary}

The STEM Research Center at Oregon State University was invited by Guerilla Science and Pratt Institute to evaluate the professional development experiences for two cohorts of science and art professionals. Each professional development experience consisted of a three-day workshop and field experience in August and September 2019. We used workshop observation, workshop postsurveys, field experience post surveys, and a six month follow-up survey to provide feedback about: 1) the quality and usefulness of the professional development experience for participants, and 2) effectiveness of the professional development experience for achieving the key participant outcomes of increased dispositions to and increased self-efficacy in three areas:

- Creating experiences that live in the intersection of science and theatre

- Creating experiences that connect to the emotions and interests of the audience

- Creating experiences that communicate science in non-science settings.

The majority of the respondents enjoyed and valued both the workshop and the field experience. They felt excited and inspired and felt they took away useful ideas, tools, and potential collaborations that would help them in their work. They discussed the networking, ideas and practical tips for developing public engagement experiences, and having a "safe place where we could fail and learn" as especially helpful elements of their professional development experience. However, participants expressed disappointment and frustration that they did not get more time for creative collaboration and to work on a new science-art experience they could use in their own situation. Many participants had expected more making and creating together based on the advertisement and recruitment information about the workshop. Most of the same participants who expressed these disappointments, still expressed having a positive experience. After the workshop and field experience, a majority of respondents to the survey reported they felt more committed, prepared, excited, and confident about creating experiences that live in the intersection of science and theatre, connect to the emotions and interests of the audience, and that communicate science in non-science settings. Several participants shared examples of the public engagement activities they conducted after the professional development experience. We provide several recommendations for future professional development, including the incorporation of more opportunities for creating and making in a collaborative, interdisciplinary way, building up and expanding upon the successful networking aspect of the experience, and development and advertisement of clearer objectives. 


\section{Key Findings}

- Most participants identified as either scientists or science communicators with many fewer identifying as creative professionals. Participants applied for the workshop and field experience for a variety of reasons, including to network with other professionals, seek inspiration for bridging/connecting art and science, and to explore innovative ways to do science communication.

- The majority of the participants who responded to the surveys enjoyed and valued both the workshop and the field experience. They felt excited and inspired and felt they took away useful ideas, tools, and potential collaborations that would help them in their work. They discussed the networking, the ideas and practical tips for developing public engagement experiences, and having a "safe place where we could fail and learn" as especially helpful elements of their professional development experience.

- Many participants expressed disappointment and frustration that they did not get to do more creative collaboration and work on a new science-art experience they could use in their own situation. Many participants had expected more making and creating together based on the advertisement and recruitment information about the workshop. Also, some participants did not connect to the focus on theatre and live experiences because they did not see ways to apply those ideas in their own public engagement work. However, most of the same participants who expressed these disappointments still said they had a positive experience. We conclude that Guerilla Science and Pratt Institute have a window of opportunity to offer a different kind of experience focused more on creative collaboration and building experiences from scratch in the future.

- Participants overwhelmingly reported that since participating in Conveying Science Through Art: A Public Engagement Workshop and Field Experience, they were more committed, prepared, confident, and excited about creating experiences that: 1) live in the intersection of science and theatre, 2) connect to the emotions and interests of the audience, and 3) communicate science in non-science settings. Not a single participant reported less commitment, preparation, confidence, or excitement since participating in the professional development experience.

- The concept of creating an audience-centered experience resonated strongly with the participants. They expressed strong intention for creating an experience that connects to emotions and interests of the audiences in the next 12 months, and this concept was often mentioned in open-ended answers about their takeaways.

- We provide several recommendations for future professional development in the conclusions, including the incorporation of more opportunities for creating and making in a collaborative, interdisciplinary way, building up and expanding upon the successful 
networking aspect of the experience, and development and advertisement of clearer objectives.

\section{Scope of the Study}

This evaluation project focused on providing feedback about: 1) the quality and usefulness of the professional development experience for participants, and 2) effectiveness of the professional development experience for achieving the key participant outcomes of increased disposition to and self-efficacy in three areas:

- Creating experiences that live in the intersection of science and theatre

- Creating experiences that connect to the emotions and interests of the audience

- Creating experiences that communicate science in non-science settings

Data were gathered from two cohorts of participants in workshop and field experience sessions during August and September 2019. Formative feedback was already shared with Guerilla Science and Pratt Institute after the August workshop. This report presents the summative evaluation results from the workshop and field experience for both cohorts. 
Results

\section{Participant Characterization}

To understand more about the participants who chose to take part in Conveying Science through Art workshop and field experience, we asked questions about their motivation for participating in the experience, with which profession they identify the most, and how much time they spend on public engagement.

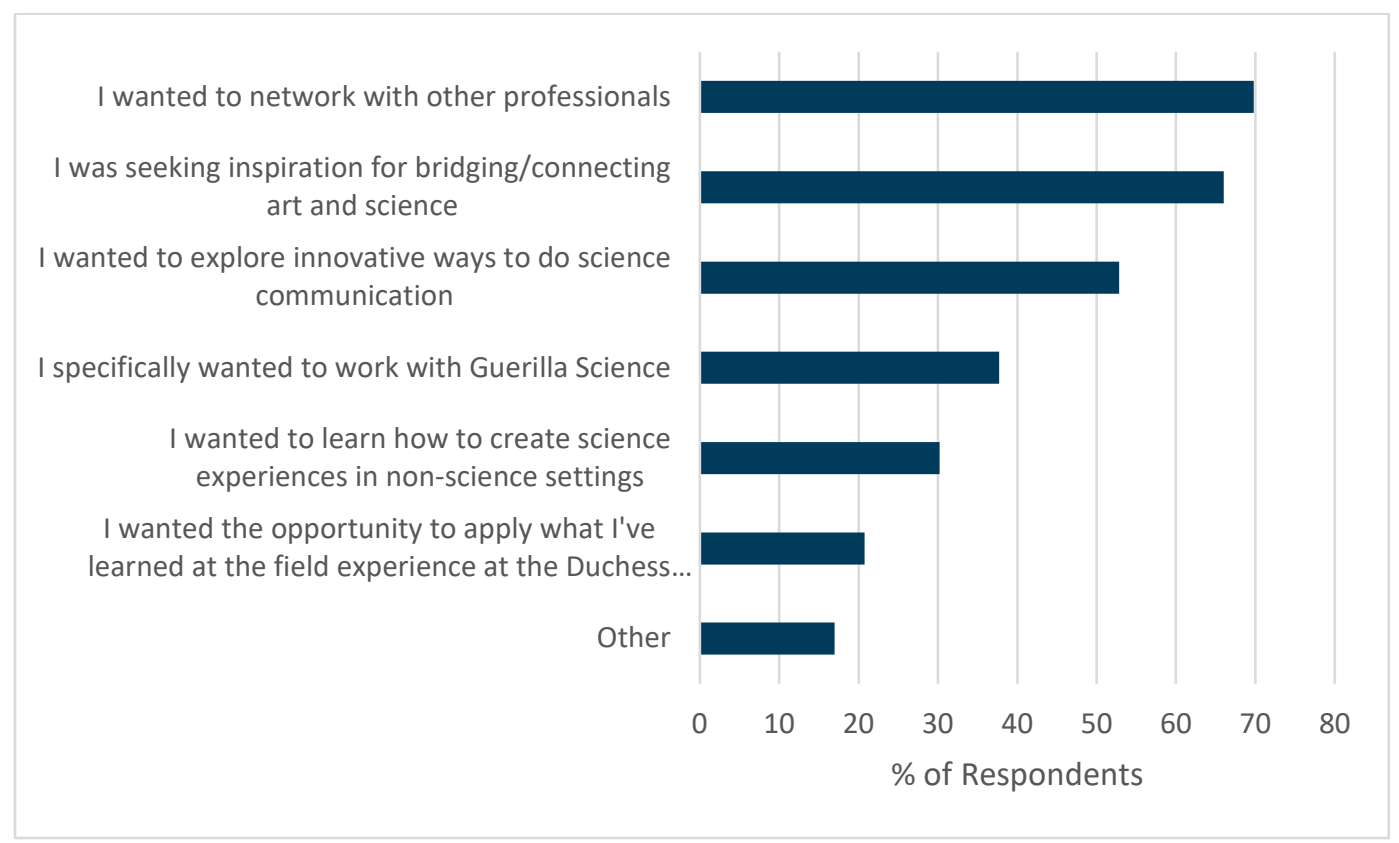

Figure 1. What mostly brought you to Conveying Science through Art: A Public Engagement Workshop and Field Experience? Select all that apply. $n=53$.

Participants applied for the workshop and field experience for a variety of reasons, including to network with other professionals, seek inspiration for bridging/connecting art and science, and to explore innovative ways to do science communication as the top three chosen. Other responses included:

- To expand their knowledge of science

- To see practical applications of science-art collaborations to convey scientific messages and logistics, techniques, types of art appropriate for that purpose

- To learn more about the design and production end of creating science experiences, rather than just facilitating them

- To improve their science outreach skills 


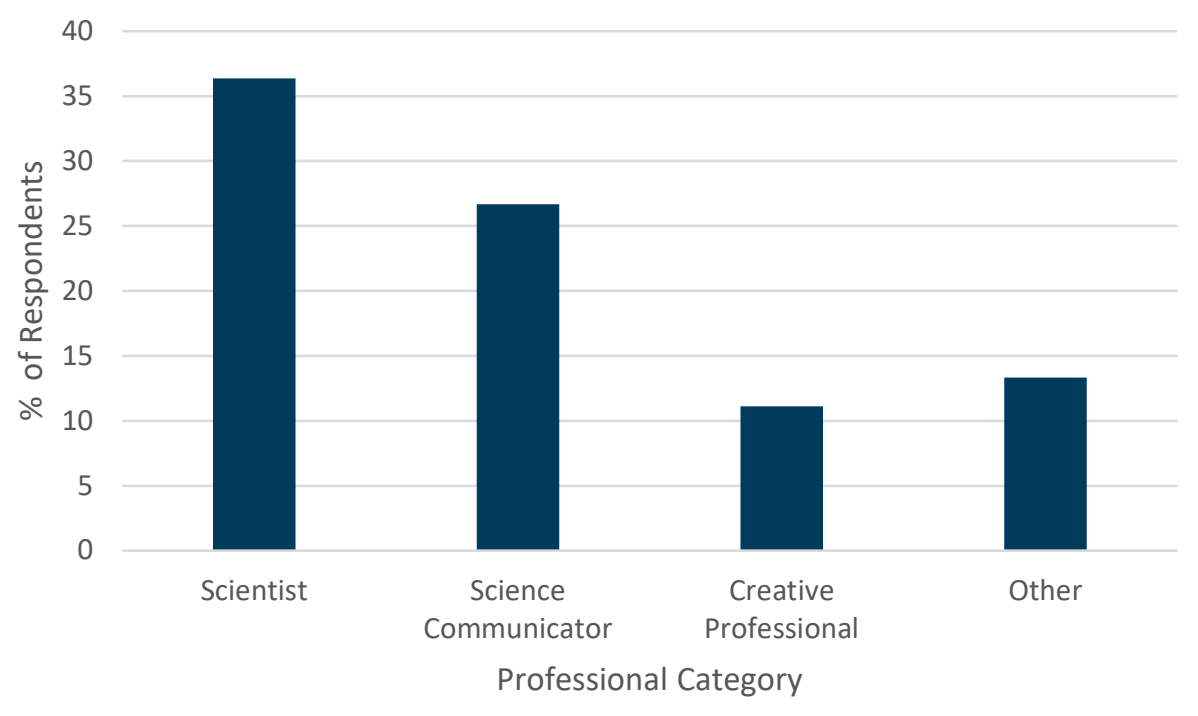

Figure 2. With which of these categories do you most identify? $n=43$.

Participants identified as scientists (36\%), science communicators (27\%), creative professionals (11\%), or other (13\%). Participants reported spending a wide range of time on public engagement with a mean (34\%), max (100\%), minimum (0\%), and median of $25 \%$. A majority of the respondents (68\%) reported they consider public engagement a part of their job description.

\section{Quality and Usefulness of the Workshop and Field Experience}

The majority of the respondents enjoyed and valued both the workshop and the field experience. They felt excited and inspired and felt they took away useful ideas, tools, and potential collaborations that would help them in their work.

Both the workshop and whole experience had more promoters than detractors (Figure 3). Data for Figure 3 are based on Net Promoter Score calculations, and represent participants' satisfaction. To measure satisfaction, participants were asked to rate their agreement on a scale from 1 to 10 on three statements: "I would recommend this event to a friend.", "I would attend/take part in an event like this again.", and "I am satisfied with this event." Individuals who have an average (over all three statements) of 9 or 10 are considered "Promoters": they had such a positive experience that they will tell others about it and actively recruit others to engage. Those with scores of 7 or 8 are considered "Passive": they were satisfied with their experience, but will not become a spokesperson. Finally, those with an average score of 6 and below are considered "Detractors": these individuals were unsatisfied with their experience and will share that dissatisfaction with others. It is never expected that there will be zero Detractors who walk away from engaging with an organization; the goal is simply to maximize the number of Promoters one has and successful organizations will have more Promoters than they have Detractors. 


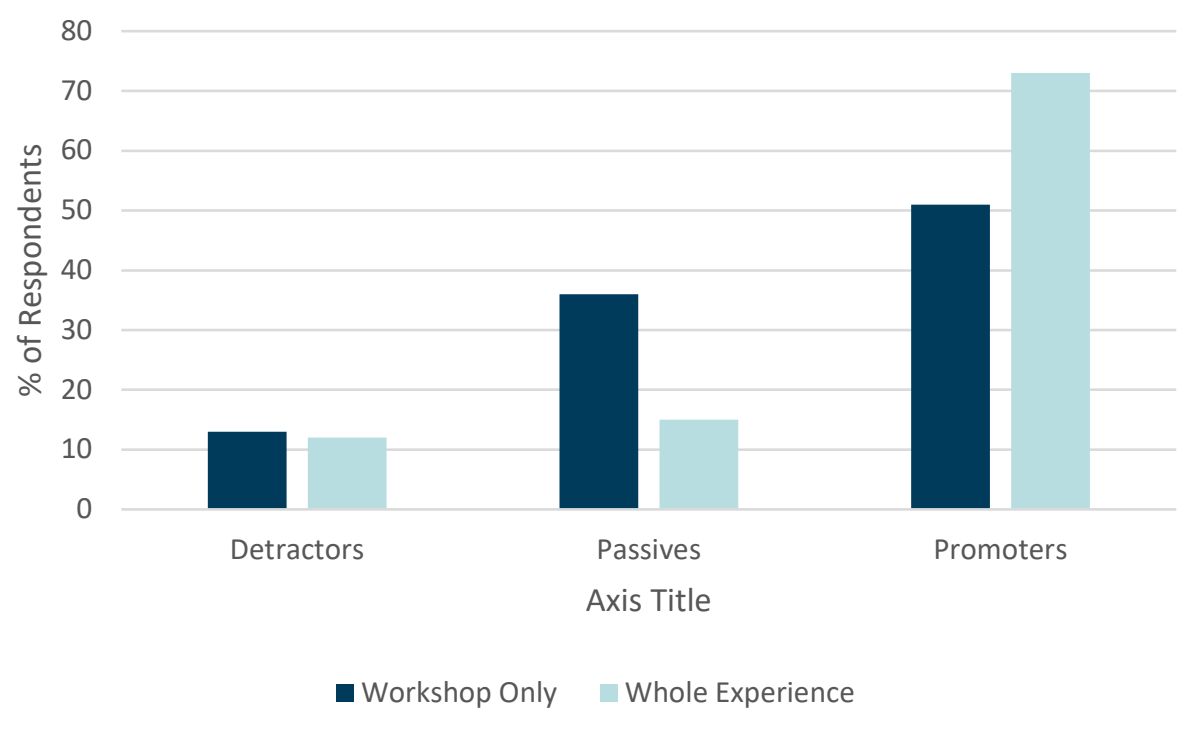

Figure 3. Percent Detractors, Passives, and Promoters for Workshop Only $(n=53)$, and for Whole Experience (workshop and field Experience; $n=26$ ).

We asked participants if they got what they hoped out of the experience both after just the workshop and after the whole professional development experience. Three strong themes emerged in their responses.

First, almost all of the participants discussed that the reason they participated in the experience was for networking (see also Figure 1), and a majority of participants mentioned that the workshop and field experience successfully met their hopes for networking. For example, one participant noted that, "I definitely wanted to expand my network of science/creative people. This was absolutely accomplished." Another participant stated, "It was helpful to hear from like-minded individuals about frustrations, barriers, and ways forward in integrating art and science in their worlds. Engaging with others from different backgrounds in the arts and sciences was extremely helpful as well." Some participants mentioned plans for collaboration after the workshop. For example, one participant mentioned that, "I finish the workshop feeling inspired and motivated. The new connections have been delightful and unexpected, and I intend to pursue them." Another participant asked for a "networking mailing list to stay in touch" with other participants after the workshop." In the six-month delayed post survey, one participant said, "I am very grateful for the people I have met during this workshop. I am still in touch with some of them."

Second, some participants stated that they got ideas and practical tips for developing public engagement experiences like they hoped. For example, one participant noted that "the workshop was really practical and gave us a lot of hands-on ways to develop experiences." Another participant described that, "I got a lot of ideas for how to better create immersive experiences, [and] think about ways to reach audiences." In the six-month delayed post survey, one participant said they "recently came across the Workshop Materials that we were handed out ant the exercise that we did. They were very useful and insightful. I still keep them on file to review." 
Thirdly, many participants expressed disappointment and frustration that they did not get to do more creative collaboration and work on a new science-art experience they could use in their own situation. One participant said, "My expectation going in was more of a collaborative creative experience/process. I thought we would be working together to come up with ideas, not to recreate already existing ideas." Another participant noted that, "I had hoped for more create time to workshop ideas and art into my own science communication, but only 15 minutes during the 3 day experience was allotted for this, which I felt was actually a bit stifling because I wanted so badly to do that." In the six-month delayed post survey, one participant mentioned, "I would have liked for the workshop to have a component where we can work on a personal project for our own community."

When asked what parts of the workshop and field experience were most helpful in achieving their goals, common themes mentioned were: lunchtime talks, the field experience, and networking. For example, participants wanted information about the mechanics of developing and implementing an experience, especially with examples of starter experiences for those who don't have the training and resources of Guerilla Science, and expressed that the lunchtime talks were most helpful in getting this kind of information. Many participants mentioned that the field experience was very helpful as an opportunity for "learning through doing" and having a "safe place where we could fail and learn." Almost everyone commented on how well the networking part of the experience worked for them.

When asked what parts of the workshop and field experience were least helpful in achieving their goals, respondents discussed the following themes: 1) less theory, more practical work, 2) more time for art and creative construction and collaboration, 3) later start times for the workshop (particularly for September since it was almost entirely over a weekend), 4) more clearly organized sessions for the prototyping and role playing on days two and three, and 5) logistics and communication issues around the field experiences.

Participants were asked to indicate how useful they found workshop sessions for meeting their goals (Figures 4 and 5). Data are presented separately because the layout of the two workshops was slightly different. However, common patterns emerged from the data. Overall, the lowest scores were for day one, especially in August. The overall highest scores were on day three, although in September participants did not find prototyping and creative time quite as useful. These patterns also emerged in open-ended data in that participants thought that too much time in the workshop was spent on theory compared to practical work. Overall, respondents gave lower scores for August compared to the September workshop likely because Guerilla Science incorporated formative feedback to improve the workshop for September. 


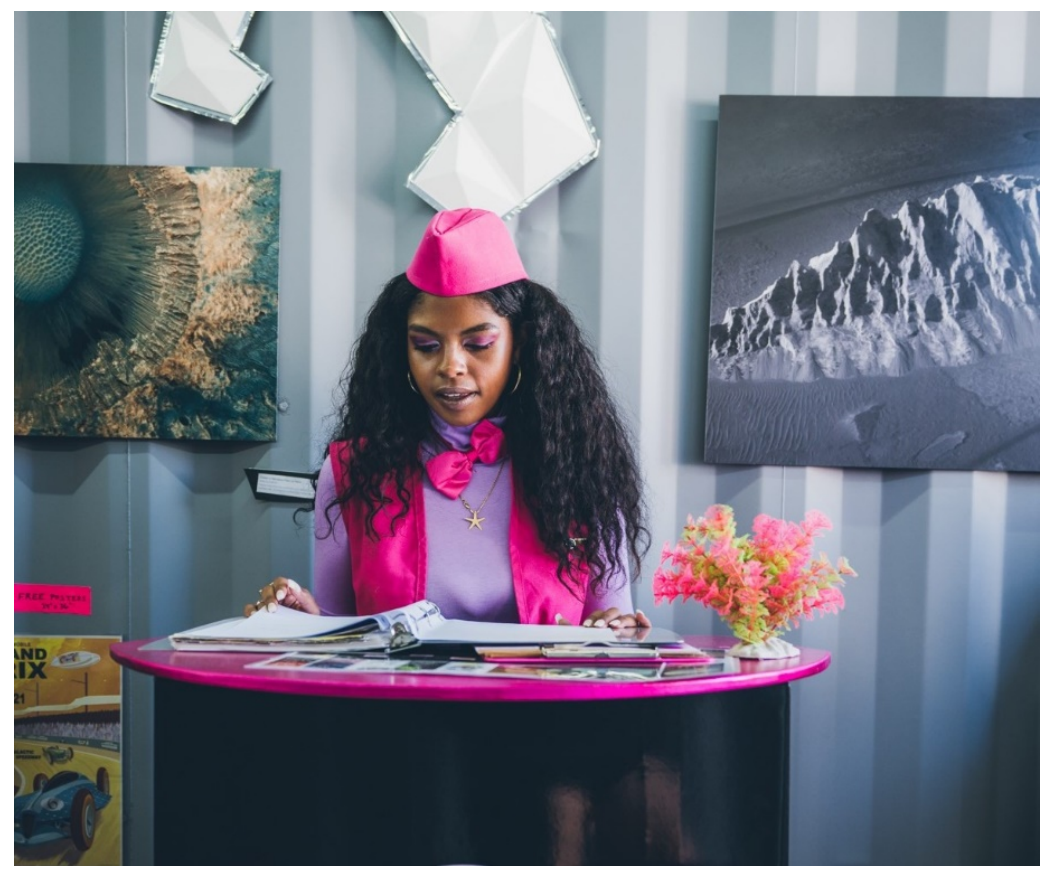

Guerilla Science training programs include hands-on elements of experience, costume, and set design that helps science communicators develop high production-value projects that members of the public are instinctively drawn to as a form of entertainment. Here, participants AnneMarie Hagenaars (scientist and actress, top) at the Intergalactic Travel Bureau of Photoville 2019.

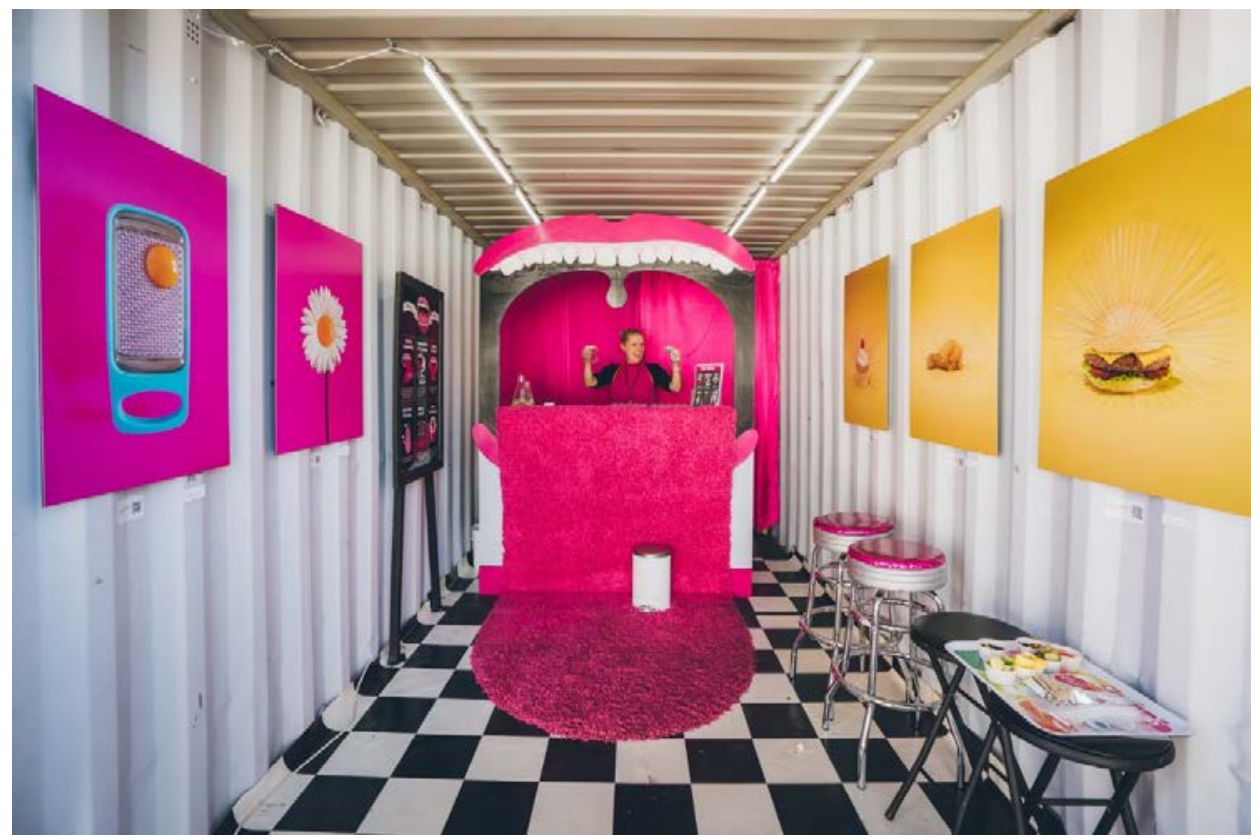

Tiffany Hamm (science education PhD student) poses with the Flavor Feast of Photoville 2019. 


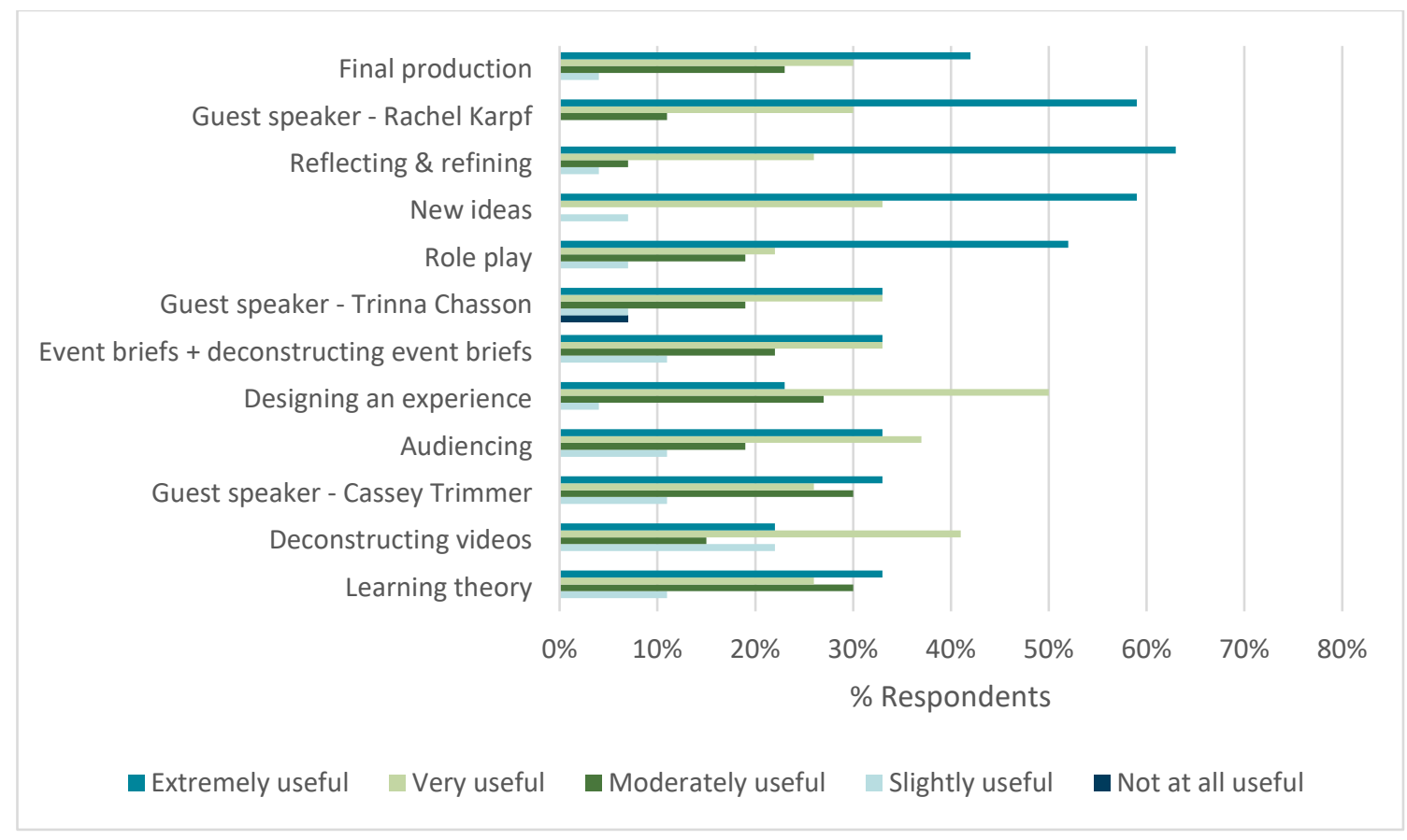

Figure 4. Respondents' answers to, "Please indicate how useful you found the below sessions for meeting your goals for the Conveying Science through Art: A Public Engagement Workshop." Data from August workshop only. Totals do not add up to $100 \%$ because of rounding. $n=27$

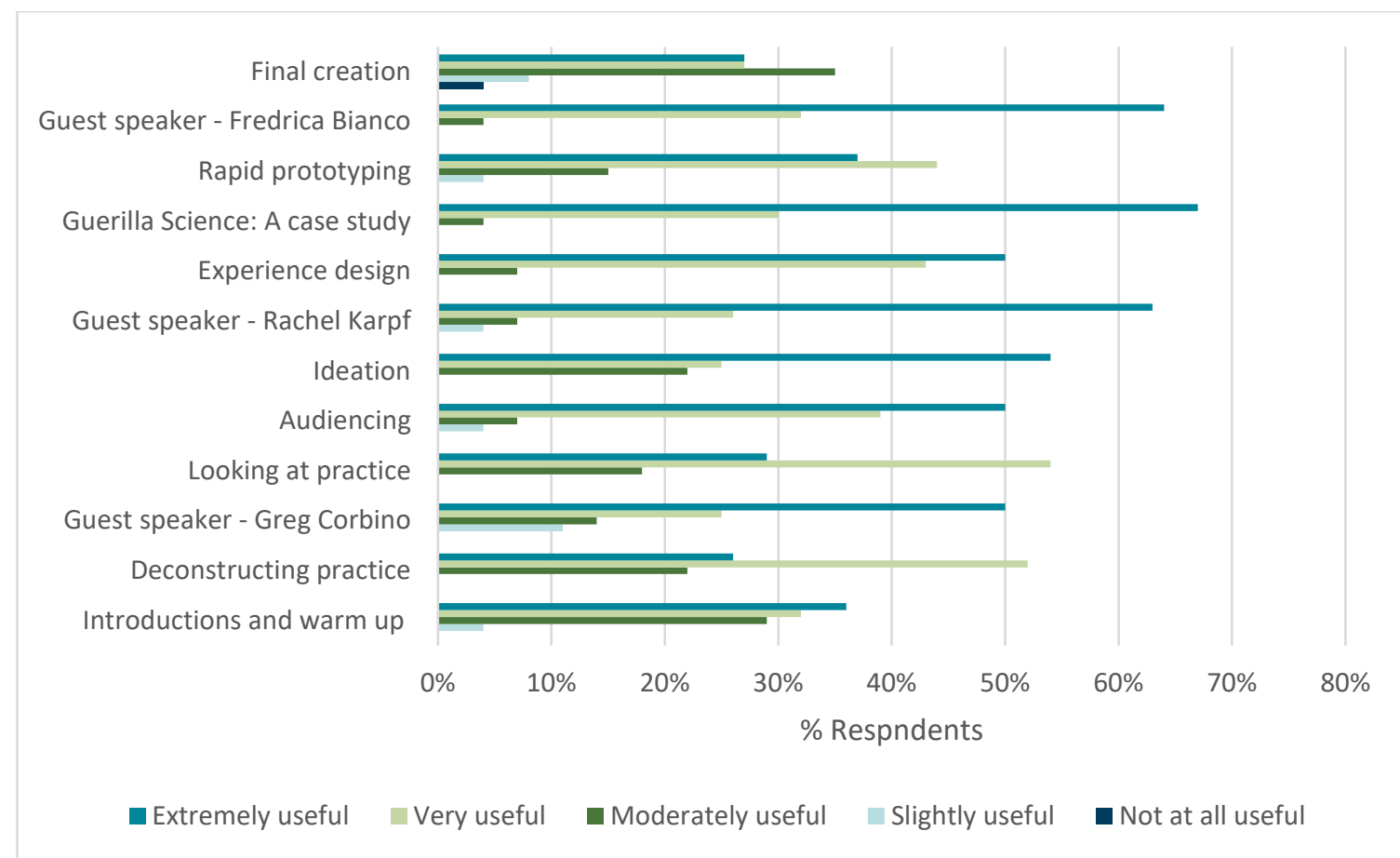

Figure 5. Respondents' answers to, "Please indicate how useful you found the below sessions for meeting your goals for the Conveying Science through Art: A Public Engagement Workshop." Data from September workshop only. Totals do not add up to $100 \%$ because of rounding. $n=26$. 


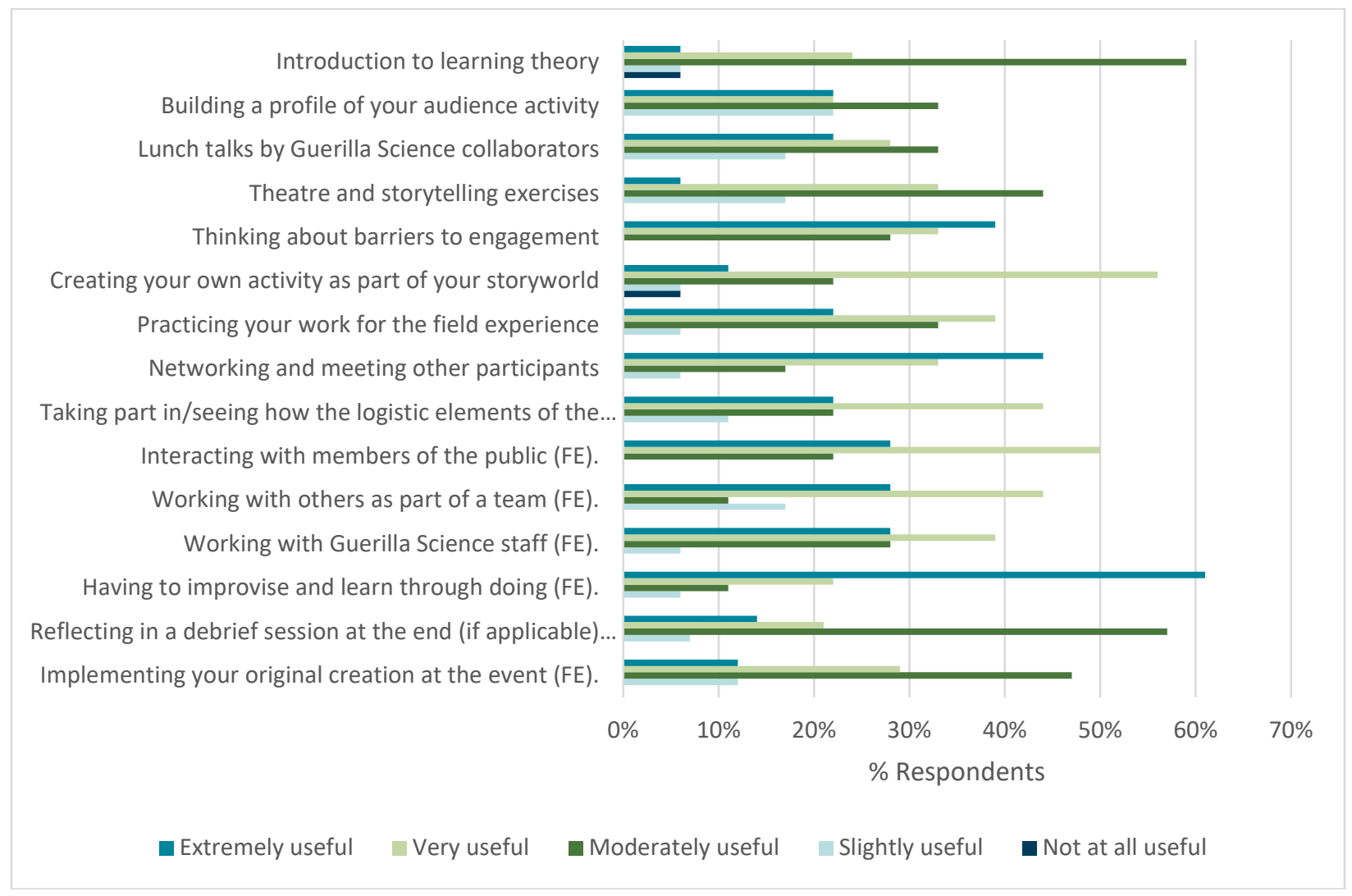

Figure 6. Respondents' answers to, “Thinking back on the support you received from Guerilla Science, including the workshop at New York Academy of Sciences and the field experience (designated by FE), indicate how useful you found the below elements of support to the event or activity you led or the event or activity you are planning?" $n=18$.

When asked to reflect back on the support they received from Guerilla Science, including the workshop and field experience (Figure 6), participants identified that having to improvise and learn through doing during the field experience (83\% total rated extremely or very useful), closely followed by interacting with members of the public during the field experience $(78 \%)$, and networking and meeting other participants during the workshop (77\%) were rated most useful. Participants also identified working with others as part of a team during the field experience and thinking about barriers to engagement (both with $72 \%$ total rated extremely or very useful), as useful. Participants identified time spent on learning theory in the workshop as least useful (30\% total rated extremely or very useful). Overall, respondents to the delayed post-survey gave higher ratings of usefulness to the field experience than the workshop.

\section{Participant Takeaways}

Participants overwhelmingly reported that since participating in Conveying Science Through Art: A Public Engagement Workshop and Field Experience, they were more committed, prepared, confident, and excited about creating experiences that: 1 ) live in the intersection of science and 
theatre, 2) connect to the emotions and interests of the audience, and 3) communicate science in non-science settings (See Figures 7 - 9). Not a single participant reported less commitment, preparation, confidence, or excitement since participating in the professional development experience. The fact that respondents rated less commitment, preparation, confidence, and excitement for creating experiences that live in the intersection of science and theatre (Figure 7) as compared to the other categories (Figures 8 \& 9) fits with open-ended responses expressing that theatre and experience design were not forms of art with which they connect. For example, one participant noted that,

This workshop was very focused on the carnival/performative aspect and I didn't feel it could help me in my particular setting, which is working with university and high school art and design students who are asked to do the science and implement it in the respective courses of study.

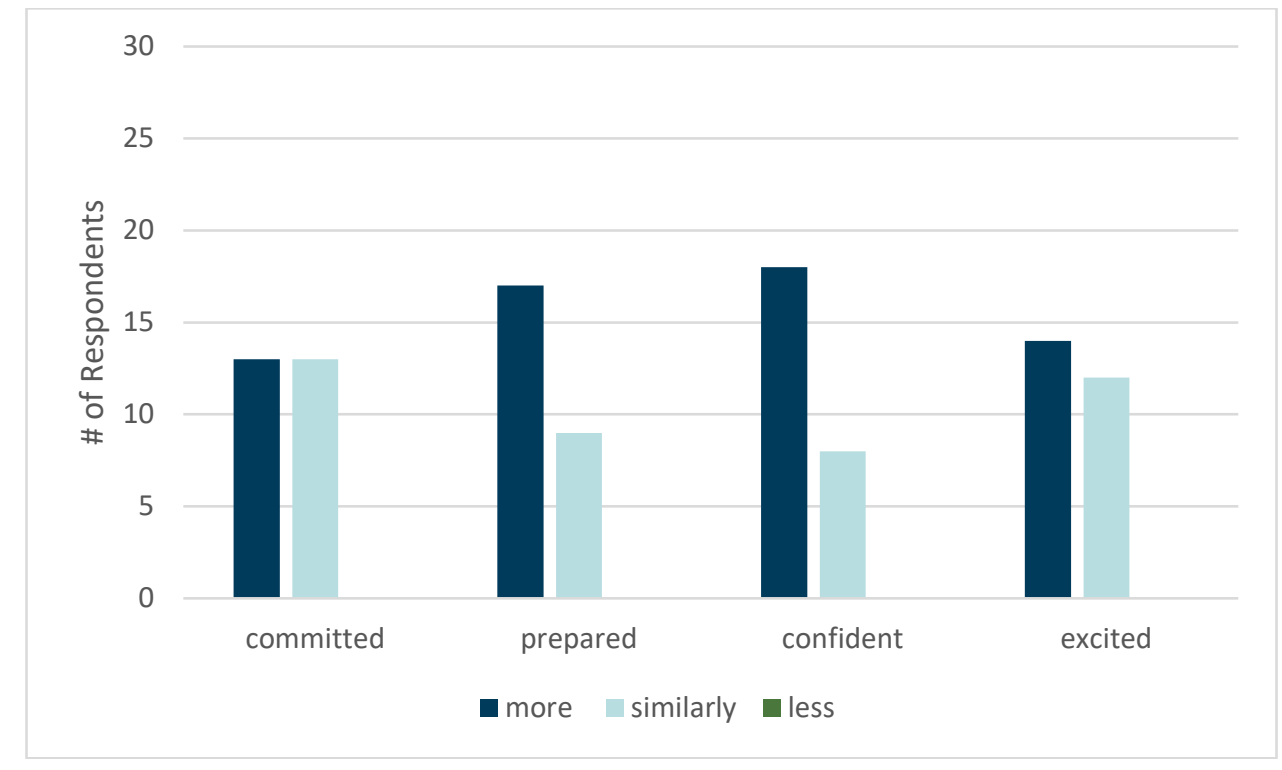

Figure 7. Since participating in Conveying Science through Art: A Public Engagement Workshop and Field Experience, what is your level of commitment, preparation, confidence, and excitement for creating experiences that live in the intersection of science and theatre? $\mathrm{n}=\mathbf{2 6}$. 


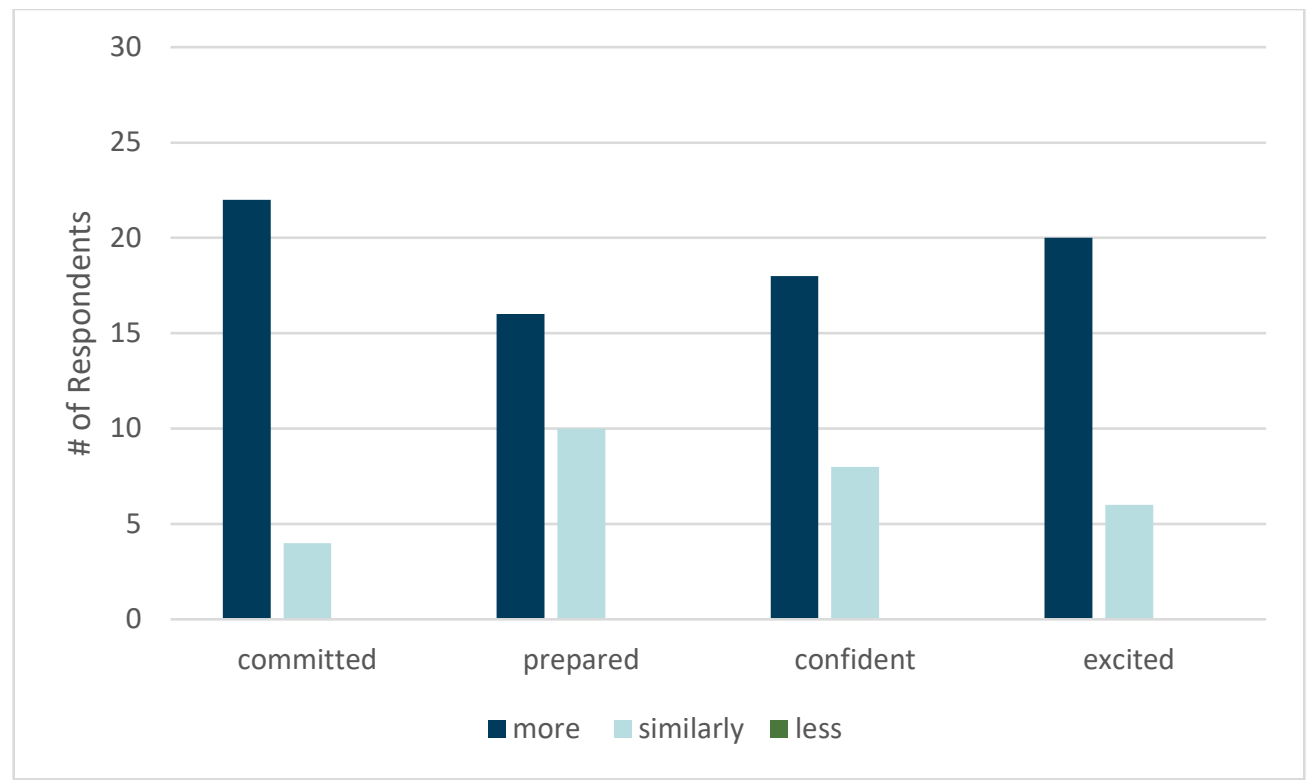

Figure 8. Since participating in Conveying Science through Art: A Public Engagement Workshop and Field Experience, what is your level of commitment, preparation, confidence, and excitement for creating experiences that connect to the emotions and interests of the audience? $n=26$.

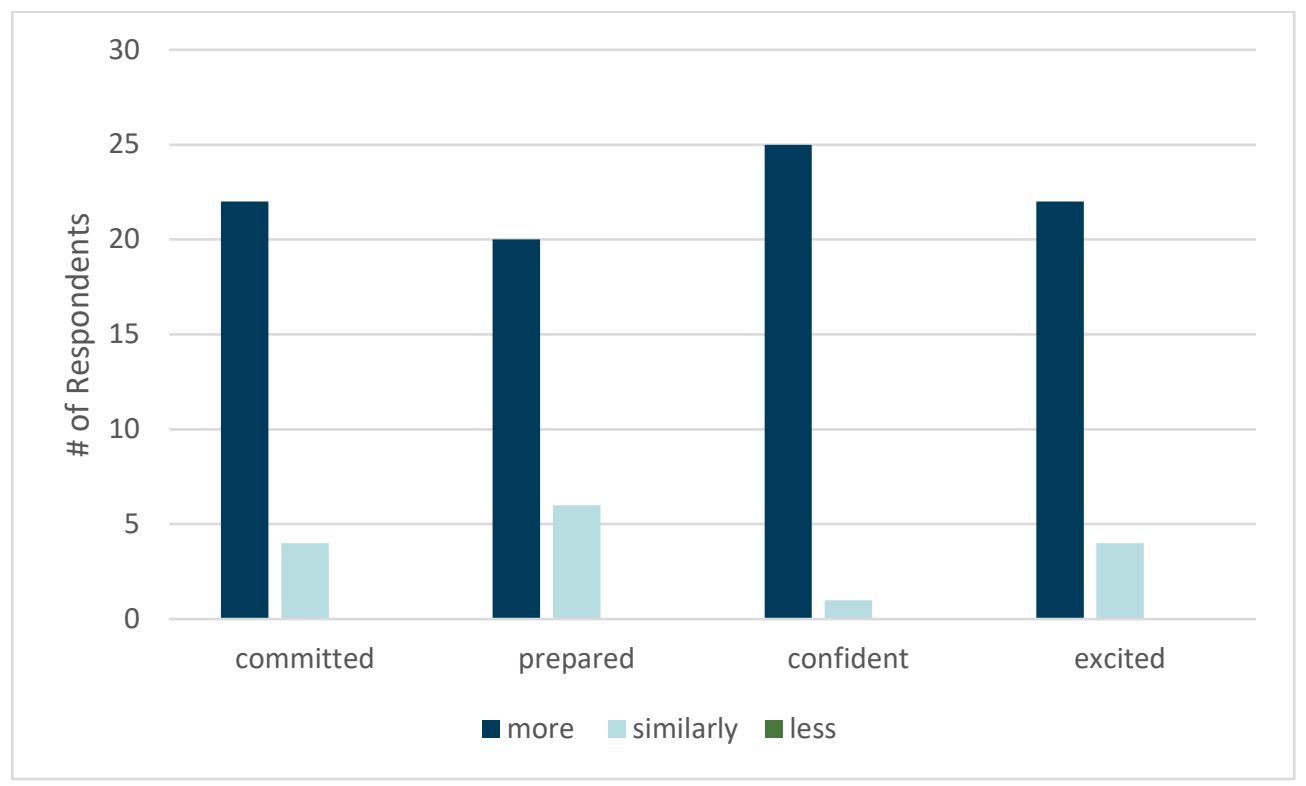

Figure 9. Since participating in Conveying Science through Art: A Public Engagement Workshop and Field Experience, what is your level of commitment, preparation, confidence, and excitement for creating experiences that communicate science in non-science settings? $\mathrm{n}=26$.

In addition to the quantitative data presented in Figures 7-9, three themes from the open-ended data emerged as major takeaways from the workshop and field experience. First, many participants discussed ways to think about and create an audience-centered experience as a takeaway. For 
example, one participant mentioned, "my main takeaway was to make sure to focus on the enduser's input vs. being overly excited to share what excites me (whether or not they care)." Another participant discussed that when you design an experience you must recognize that "participants enter in various stages of understanding," and you should "really think through all the small details to make sure everyone feels included." In part, these takeaways seemed to emerge from the opportunity to apply what they learned at the workshop in the field experience. For example, a participant noted that, "the field experience showed me that I had to be flexible with my engagement and adapt to the tone that was being set by the visitors." In the six-month delayed post survey, a participant mentioned that the "biggest takeaway I got from the event long-term was learning about the different publics, and profiling them for events."

Secondly, many participants discussed inspiration and excitement as a takeaway. For example, one participant mentioned that their takeaway from the workshop and field experience was a, "renewed energy for creating immersive and meaningful science engagement experiences." Another participant said that "science communication can be fun, exciting, and engaging."

Thirdly, many participants discussed that science can be fun. One participant summed up the third theme very succinctly: "a level of play can really engage and entice people to engage with science."

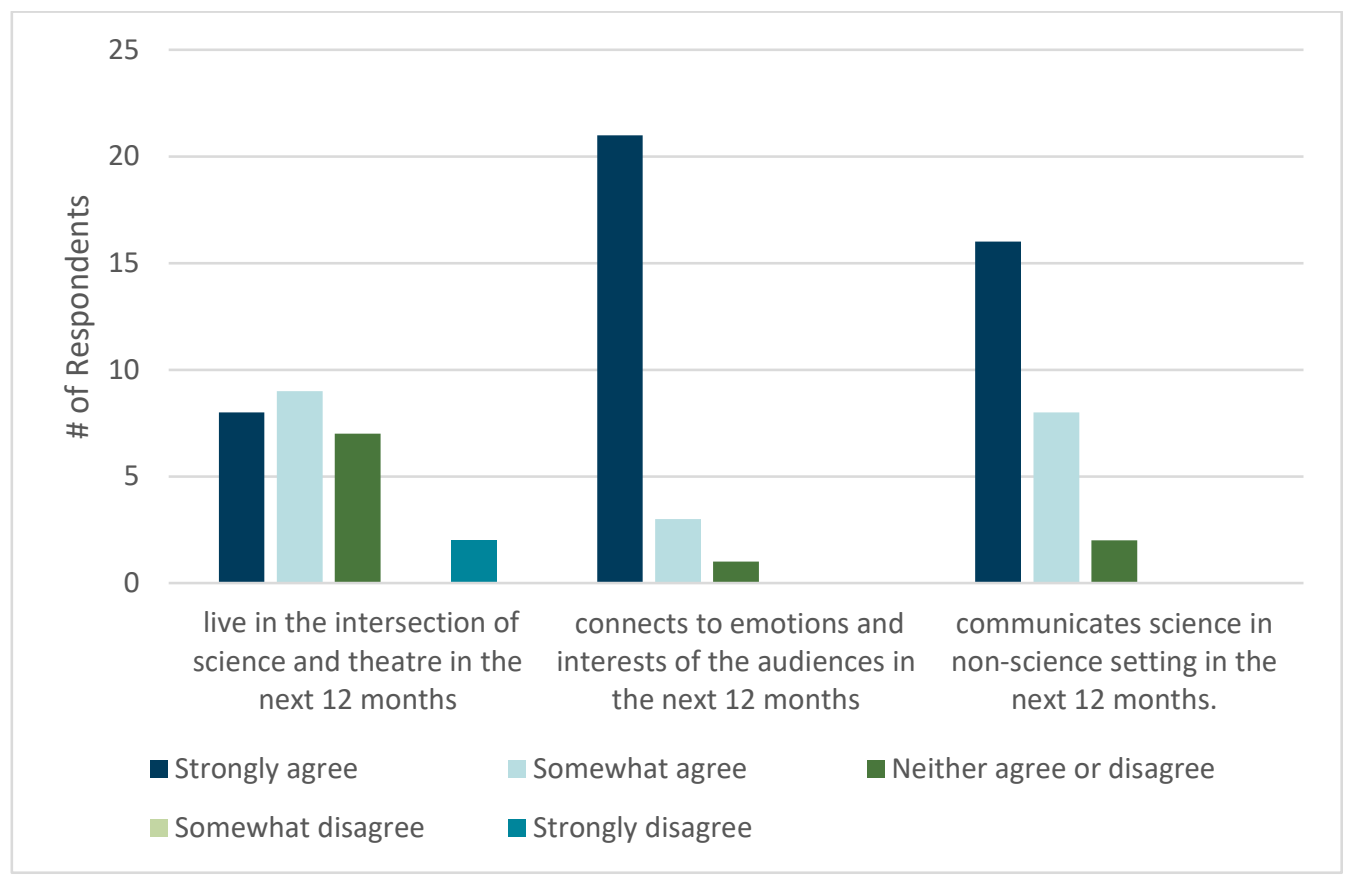

Figure 10. Responses to a Likert scale question about intention. Figure shows data from three questions that all started with, "Since participating in Conveying Science through Art: A Public Engagement Workshop and Field Experience, $\mathrm{I}$ intend to create an experience(s) that....." $n=26$. 
Respondents expressed strongest intention for creating an experience that connects to emotions and interests of the audiences in the next 12 months (Figure 10). This takeaway was also often mentioned in open-ended answers about their takeaways (see above). Intentions were not nearly as strong for creating an experience that lives in the intersection of science and theatre in the next 12 months, which is also supported in data presented in Figures 7-9.

Professional Identity: Scientist-artist-instructor striving to be a science communicator

Public engagement event: The event was a SciArt exhibition with my Science Art and Society students. We explored the periodic table as inspiration to honor it's 150 year anniversary. We also explored plant synthetic biology as a means to produced manufactured goods in a new way.

What do you wish you would have known from the beginning?

How far in advance one has to book a site, costs, and how best to advertise.

\section{Professional Identity: Scientist}

Public Engagement Event: The event was a public talk at an art gallery relating Shakespeare, Surrealism, and Science.

What do you wish you would have known from the beginning? That I can use broad concepts that transcend art or science to engage with the public.

\section{Professional identity: Science Communicator}

Public Engagement Event: The event was a Jazz + Neuroscience event at the National Jazz Museum in Harlem and combining art + neuroscience in our education lab.

What do you wish you would have known from the beginning? More about the audience.

Figure 11. Examples of public engagement events facilitated by participants in the six months after the professional development experience and their reflection about what they wished they knew from the beginning. 


\section{Conclusion}

\section{Concluding on Evaluation Questions}

In conclusion, this evaluation provided feedback about: 1) the quality and usefulness of the professional development experience for participants, and 2) effectiveness of the professional development experience for achieving the key participant outcomes of increased dispositions to and increased self-efficacy in three areas:

- Creating experiences that live in the intersection of science and theatre

- Creating experiences that connect to the emotions and interests of the audience

- Creating experiences that communicate science in non-science settings.

For the first evaluation question, the results showed that Guerilla Science and Pratt Institute delivered a high quality and useful professional development experience with some lessons learned. Participants gave very high satisfaction scores and rated most elements of the workshop as very or extremely useful. One participant summed up their experience (and the experience of many others) in this way,

My brain has been exploding with excitement and inspiration, and I feel validated and cosmically seen by the universe to be here and have nuanced conversations about things I care about so much with humans that are equally invested.

For the second evaluation question, results showed that the professional development experience was very effective in achieving the key participant outcomes of increased dispositions to and increased self-efficacy in creating experiences that live in the intersection of science and theatre, that connect to the emotions and interests of the audience and that communicate science in nonscience settings. A majority of respondents to the survey reported they felt more committed, more prepared, more excited, and more confident about creating experiences that live in the intersection of science and theatre, connect to the emotions and interests of the audience, and that communicate science in non-science settings.

\section{Recommendations for Future Professional Development}

We highlight several recommendations for future professional development:

1. Build in even more opportunities for informal and formal networking. Consider breaking groups up in different ways throughout the training for more ideas and perspectives to be shared and facilitating connections beyond the professional development experience.

2. Develop clearer objectives for the training and make them front and center in the recruiting and advertising. 
3. Consider developing a professional development experience that focuses more on creating and making in a collaborative, interdisciplinary way- more along the lines of a residency. Participants expressed strong interest for this kind of opportunity.

4. Build in even more practical work, and less learning theory.

5. The field experience provided a valuable opportunity for participants to apply what they learned in the workshop. Keep it! And add more and clearer framing around the field experience as an opportunity to apply what they've learned.

6. Provide how-tos and examples for several

I think Guerilla Science is in a unique position to bring together creatives and scientists, and perhaps even help with seeing projects come to life and be amplified in the real world. Not dissimilar to thinking about taking an EP (Executive Producer) role to some projects perhaps? Just thinking blue sky now... ranges of public engagement experiences: the low-budget, starting point, get your foot in the door, a mid-level example, and a highbudget example.

\section{Technical Appendix (Methods)}

In partnership with the New York Academy of Sciences and Pratt Institute, Guerilla Science conducted professional development experiences for two cohorts of scientists and art professionals. Each professional development experience consisted of a 3 day workshop and field experience with a total of 53 participants. We conducted a blended, formative/summative evaluation of the professional development experience. An OSU researcher observed the August workshop and oversaw data collection which included the following elements: post-workshop, post-workshop and field experience, and delayed post. In our analyses, we only included those respondents who completed $100 \%$ of the survey. The number of respondents included in analysis for each element of the evaluation are presented in Table A1.

Table A1. Number of respondents for each element of the evaluation.

\begin{tabular}{|c|c|c|c|}
\hline & Date & $\begin{array}{c}\text { Number of } \\
\text { Respondents }\end{array}$ & Evaluation Methods \\
\hline Post workshop & $\begin{array}{c}\text { August } 1-3,2019 \text { Sep. } \\
6-8,2019\end{array}$ & 53 & $\begin{array}{l}\text { Online Follow-up } \\
\text { Survey }\end{array}$ \\
\hline $\begin{array}{l}\text { Post Workshop + Field } \\
\text { Experience }\end{array}$ & $\begin{array}{l}\text { August } 20-26,2019 \\
\text { September } 2019 \\
\text { (various dates) }\end{array}$ & 26 & $\begin{array}{l}\text { Online Follow-Up } \\
\text { Survey }\end{array}$ \\
\hline Delayed post & $\begin{array}{c}6 \text { months after Field } \\
\text { Experience }\end{array}$ & 17 & $\begin{array}{l}\text { Online Follow-Up } \\
\text { Survey }\end{array}$ \\
\hline
\end{tabular}


We asked the following kinds of questions in the evaluation:

- To characterize the participants, we asked about:

o professional identity

o prior experience with outreach

o participant motivation

- To investigate the quality and usefulness of the professional development experience, we asked about:

o Net promoter score questions

- Usefulness of elements of the workshop

o What was most (and least) helpful for achieving the goals of the workshop

- To investigate participant takeaways,

o Self-efficacy and intention

o Main takeaways

- Descriptions of outreach they conducted post-workshop

Given the small sample size, quantitative data were analyzed using simple descriptive statistics. Open-ended data were analyzed and summarized thematically.

Note that four respondents were confused about a question on the six-month post follow-up survey. We asked them to "please answer the following question for the time frame since your participation in the Conveying Science through Art Workshop and Field Experience. Where are you in the stage of conducting a public engagement with science event or activity? For the purposes of this survey, a public engagement with science event or activity also includes an event or activity where you communicated science through the arts." Four respondents answered that yes, they had conducted one or more events or activities, but then described their field experience later in the survey so we do not report the data from this question. Note that in Figure 6 , we included the data from these four respondents as we were still interested in hearing their thoughts about the usefulness of different elements of the workshop and field experience after six months of reflection. 